\title{
FROM NATIVE TO OUTLANDER: EXPLORING INFORMAL COMMUNITY IN CHENGZHONGCUN OF CHINA
}

\author{
XUe Ni PENG, Jin BAEK \\ Seoul National University, South Korea
}

\begin{abstract}
In the existing research on Chinese migration, rural domestic Chinese migrants are often portrayed as a community of intruders with a detached culture who invade a host destination city. Usually, as a first step, they settle down in a so-called "Chengzhongcun" (literally a village encircled by the city boundaries, hereafter CZC), which is a kind of "urban village", or an undeveloped part of a city that is overshadowed by the more developed areas. The present paper tries to give an image of the rural-to-urban migrants as a more vigorous mediator that forms their migration destination. The aims are the following: first, to achieve a detailed written analysis of an existing CZC community and its functioning as a mirror of the discriminating division between the rural and urban life in China. Secondly, by taking into account the experiences of migrant communities in their host cities, this paper seeks to highlight the migrants' emotional conflict and increasing loss of values that occurs in the migration process from the rural to the urban. Thirdly, the migrants' household survival strategies shall be explored. Finally, weaving these strands together, this paper presents a case study of a Tulou collective housing project in Guangzhou Province, China.
\end{abstract}

Key Words: Chengzhongcun, individuality and community, survival strategies, the new Tulou collective housing, China.

\section{Introduction}

With China's implementation of economic reform over the past 20 years, the process of urbanization has been based on and accelerated by a mainly rural-to-urban migration flow. By 2011 , the number of the off-farm migrant workers in China totalled 253 million, which represented an increase of $4.4 \%$ (11 million) compared to 2010 (HRSSD 2011) ${ }^{1)}$. By referring to a report on China's migrant population development in 2012, we can exclude the factor of executing social institutional reforms and the partial transformation of the off-farm migrants to urban residents. By 2030, China's urbanization rate is projected to reach $65 \%$ (IEAS 2010), and in turn the number of rural migrants is expected to swell approximately 400 million (Lian 2012). It would seem that, on the one hand, high speed urban innovation acquires an expanding amount of geographic space which imposes on the surrounding arable land of rural areas; and, on the other hand, a large quantity of labor is required. These so-called urban villages are in some cases geographically located in the city in built-up areas, and, in other cases, they are near the city, but finally they are often swallowed up by the extension of the urban space. Therefore, a number of rural villages have been encompassed or annexed by the newly advancing urban territories, forming a unique entity - the CZC. Although land for agriculture no longer exists, villages where local peasants reside still remain. Nevertheless, many CZCs have been developed as informal migrant settlements in conditions that contravene the regulations of the municipal government (Li 2008).

1) These data are collected through the development statistic bulletin published by the Human Resources and Social Security Department of the PRC, 2011. 
In the process of forming a CZC, few locals or major migrants make up the actual dwellers there. Instead, Fan (2002) classifies migrants into two basic categories: those who are permanent and the temporary migrant population, a distinction which clearly depicts the dichotomy of such inhabitants. Both categories represent the most prominent examples of the 'floating population' or liudongrenkou (Goodkind and West 2002, Yu 2008). Figure 1 shows that two groups make the residents of a CZC. One, landlords - a limited number of locals are local land proprietors, among whom the majority has transformed their residential status from rural to non-rural or urban residents, even though a small minority of them remains with the status of rural households. Two, floating migrants - a large number of dwellers who belong to a group known as 'floating laborers' are composed of off-farm workers (Nongmin gong) at the bottom of the labor market (John and Song 1995), graduate students with an education or qualification (Ant group, Yizu $)^{2)}$ and Beijing vagabonds (Beipiao $)^{3)}$.

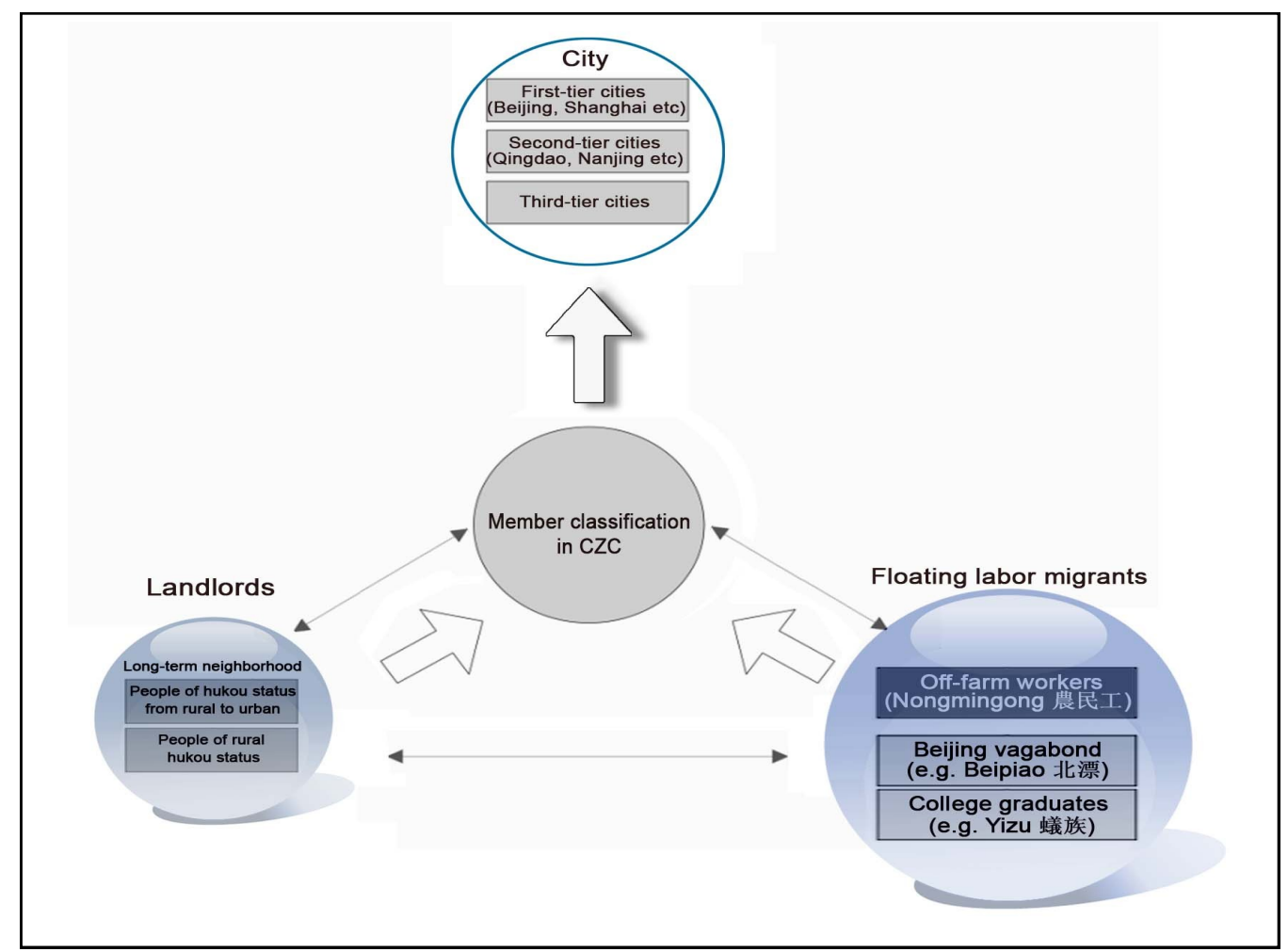

Fig. 1 - Member's classification in CZC of China

2) The term of 'Ant group' or Yizu: 蟻族, is originally used to define a mass community of the Post80 s generation of those with a better education or a well-trained background. They live a poor life without stable dwellings, normally living in collective dormitories, which are shared with other 'Ants', but they dream to live in the big cities of China.

3) Beipiao: 北漂, Literally "Beijing vagabond", regarding the community of people who do not have a Beijing hukou (household of permanent residence), who migrated to Beijing from other places of China pursuing a Beijing Dream - better opportunities and a better future. Beipiao is also the life of a drifter in Beijing. 
These migrants form a huge community, since they have arrived at their journey's destination, and their experiences have been those of a poor physical silhouette of life - full of mental, physical and economic hardships. At this juncture, I would like to draw attention to an area which has been largely overlooked by scholars, namely the way in which migrants experience their host city. I aim to consider their emotional conflict and some strategies they employ during their rural-urban migration. My understanding of the conflict results in the transformation from the egoless to the individual-full society. Recent studies of migrants focus either purely on their negative social problems or trace the inharmonious aspects of migrants' lives in China (Liu and Liang 1997). However, I believe the stereotyping of those troubles is caused by a deviation from their self-cognition, which is the ' $\mathrm{l}$ ' in the family-unit-oriented society against the ' $\mathrm{l}$ ' in the individual-full society. Therefore, the rural or Chinese traditional family patterns that I am suggesting are given a positive evaluation in the recorded list of modern urban lifestyles in China. In line with this, my study objectives in this paper are limited to the following:

- $\quad$ To build a detailed written account of the community of a CZC by noting its typical geographical location in mega-cities and show how such relocation did not merely concern itself with human's geographical moving;

- $\quad$ By means of considering the migrants' experience of a community life in the host cities, I seek to highlight the emotional conflict of their rural-urban mobility;

- $\quad$ To explore the migrants' survival strategies with regard to housing between the host city and their left-behind home;

- With reference to migrants' struggle to find suitable urban accommodation, I would like to make a suggestion to construct a specific form of lodging for migrant enclaves within a city (Xu 2008), an idea that has mostly been disregarded in the early urbanizing of China.

\section{Relocation is beyond spatial movement}

The word 'relocation' did originally refer to human moves. Rossi (1980: 18) describes a 'human move' as:

"[...] A shift in address [...] involving a shift in location through space that can vary from a few feet in the case of a shift from one apartment or room to another within a structure to thousands of miles to another country or from one end of the country to the other."

Movement (internal or external) is defined as any permanent/temporary alteration in residence. It is in this sense that in its most significant perspective it is spatial by description. Along the way, the idea of relocation has eventually acquired its sense of physical space change, and the comparatively perpetual movement of people over a noteworthy distance (Eisenstadt 1953). In short, it does not seem to be a full-scale understanding to think about domestic migration as merely a spatial change. Consideration to relocation arguments have augmented in recent years due to the influence of the population movement on household lifecycles (Bailey and Giroux 1998). Relocation can make the change from native to outlander and from in-system to out-system. This idea of relocation is ultimately extended to take in reposition that it affords a measure of re-forming the geographical and psychological alterations. Our research focuses on the rural-urban migrants' emotional conflict and increasing loss of values within the context of emerging urbanization in China as involved by the rural-urban transformation processes (Fig. 2, Fig. 3). 


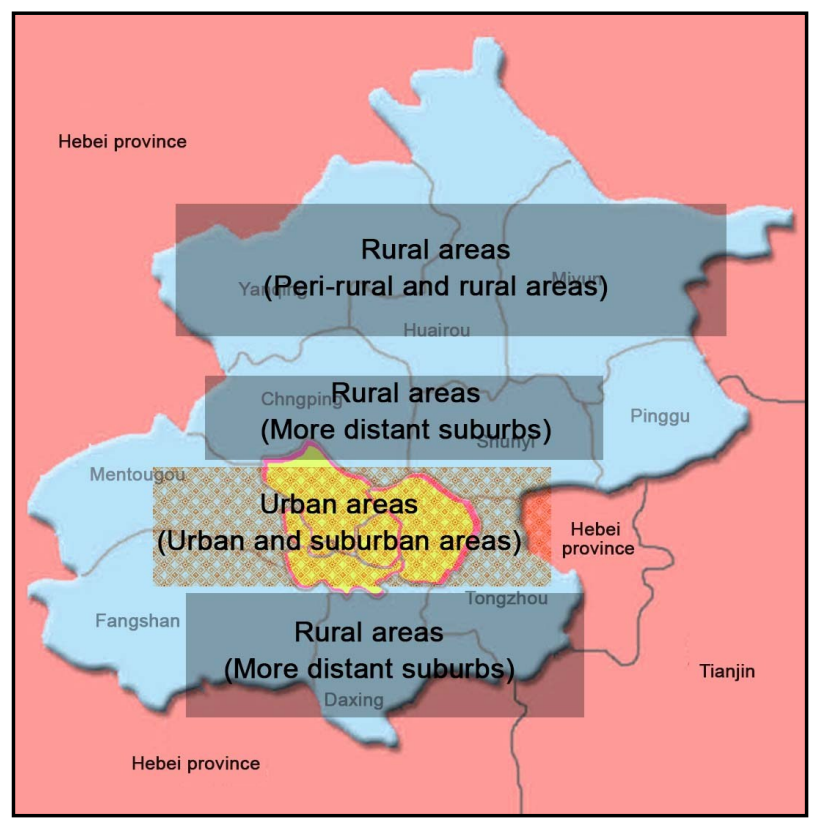

Fig. 2 - Urban areas and rural areas in Beijing Source: Zhifeng (2009)

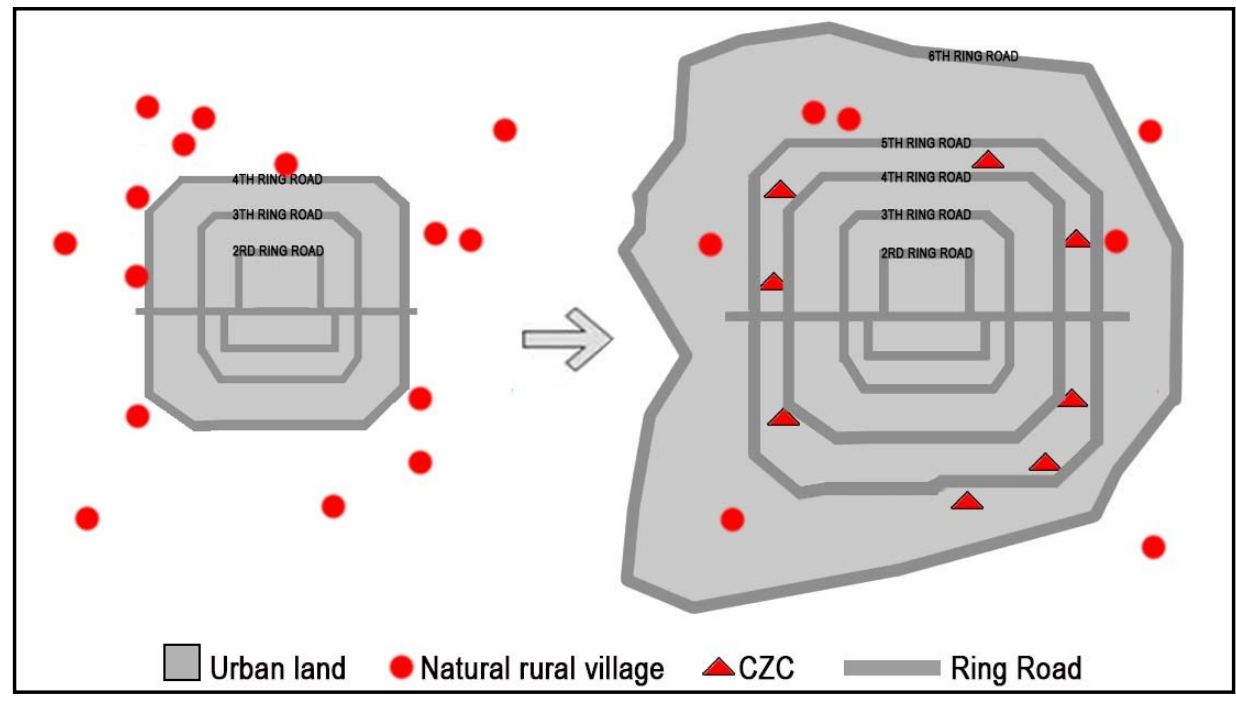

Fig. 3 - The processing of how rural villages transformed into urban villages within the urban boundary in Beijing city 
Distance and spatial borders that once functioned as a constraint to migrants have been curbed decreasingly as countrywide obstacles lowered, and they are nowadays moderated by the influence of globalization and distance by more progressive communications in terms of physical and psychological connection. Also, in migrants' narratives, "travel itself embedded an enormously significant portion of their migration experience" (Burrell 2011: 1025).

The 6th national census in China (2010) reveals that 261.39 million, or 19 percent of the whole domestic population $(1,370,536,875$ people), were temporary residents. Rail can be one of the principal means of transport (Glaeser et. al. 2008), while commercial railway transported over 1.456 billion people that travelled 772.8 billion $\mathrm{km}$ in 2008 and it carried 1.893 billion passengers in 2012. However, several trans-provincial tourists have one-way tickets. Obviously, it is challenging to differentiate migrants from travellers and calculate the exact quantity of this group. Moreover, it is now assessed as a 3.9 percent increase in quantity based on the 2011 figures, or approximately 262 million rural migrant workers in Nongmingong, as shown by the NBSC investigation report on national rural migrant workers in 2013 (NBSC 2012). Actually, working and living afield claims to be not purely a measure for achieving financial enhancement but also a progression for male and female migrants who have deliberated at variance in conjunction with the large pool of motivations, while they risk their likelihoods for their dreams (Curran and Saguy 2001).

Population movement is not new though this migration covers unheard levels: "All the world seems to be on the move", as said by Sheller and Urry (2006). This is also the case in China, especially for the most speedily urbanized cities where the issue of people's fluidity arises. For instance, the presence of migrants in the CZCs is witnessed in the long history of movement within the mainland of China. Figure 4 shows the staging of the transformation from a traditional village to a CZC over a year in the Beijing Yimuyuan neighborhood.

\section{Twilight zone: A brief note}

Through speedy urbanization, social transformation (Guo and Zhang 2006, Feng 2011) has followed with the result of a growing social inequality, the urbanization of poverty, and enormous rural-to-urban migration over the past three decades (John 2002, Laurence and Ma 2004, Li 2008). One of the crucial issues, which makes CZCs a dilemma, is their 'twilight zone' (John and Moore 1967) locations within cities. However, importance has been focused on the 'intrinsic troubles' of CZCs, such as the lack of inhabitants' self-discipline and morals in following public order, which have resulted in clashes with urban administrators.

Furthermore, a discriminatory institution - the household registration system - intensifies in essence the geographical duality in China and it deepened the conflict between the city and the countryside (Cheng and Selden 1994). That reality toughens and exploits at the same time the identities of such outsiders. In addition, most migrants fail to seek assurance of their own worth from their host community. The social categorization of migrants as outsiders stems from these institutional obstacles which by extension entail exclusion from their place of origin.

On the one hand, this exclusion includes the urban society's rejection of a certain group of migrants, in particular off-farm migrants. Such discrimination against migrant groups is mirrored in terms of urbanites' attitude of exclusion towards migrants in general and disparate treatment and refusal to build equivalent social relationships with outsiders. On the other hand, the urban community bestows little social worth, recognition or sense of belonging to migrants. Therefore, for the floating migrants, their social links and community participation, as well as their 


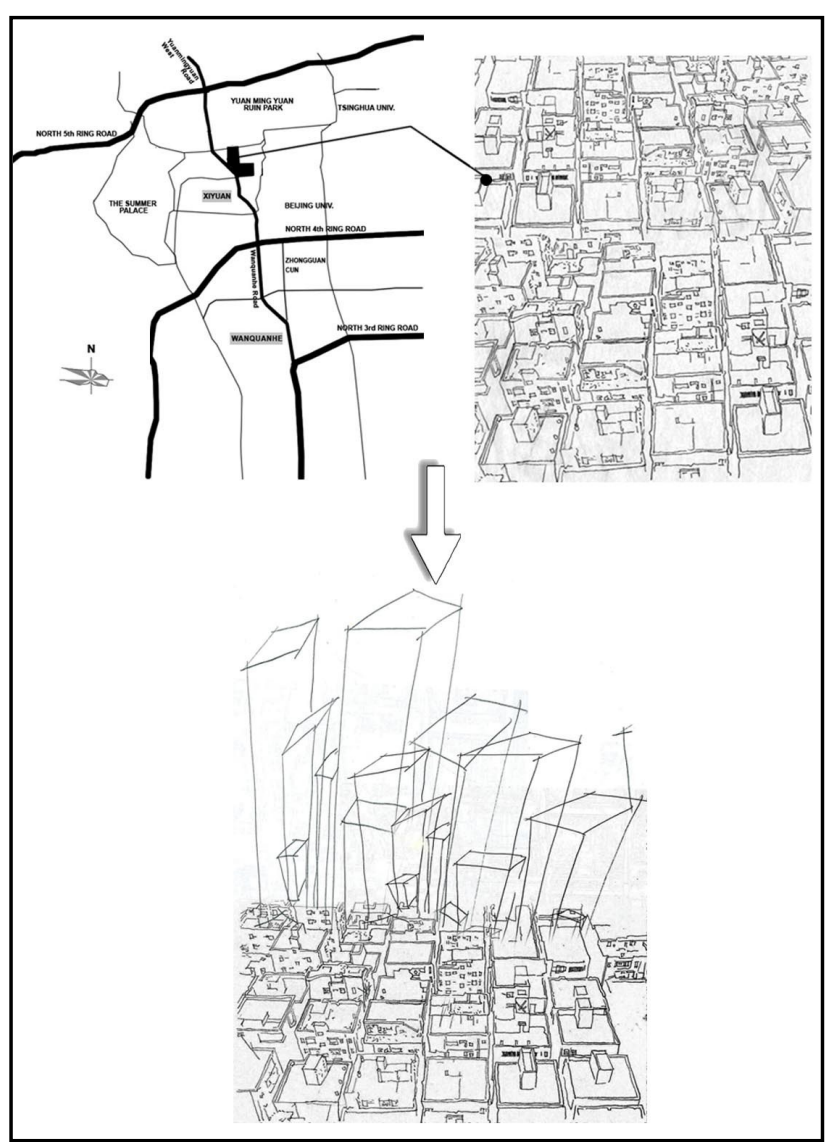

Fig. 4 - Typical plot viewing the staging of increasing over-compacted buildings over the years in Beijing Yimuyuan neighborhood, China

subjective awareness of social belonging, are likewise discouraged or dampened due to being part of the invisible periphery.

Moreover, my understanding of 'invisible periphery' stems from what Michel Foucault (1990) proposes as the 'techniques of the self' concerning the community bounded by one's concurrent consciousness of their relation to the internal of the external and/or the exterior of the interior. Thus, through this awareness, it projects within ourselves who we are to ourselves and to other people. Finally, this person conducts him/herself and acts through his/her day-today experience with such rules (Foucault 1990). That is to say, 'invisible periphery' can be considered a community experienced differently by natives and non-locals. Through the perceivable difference, the mutual parts will locate their selves and others. Lastly, this projects on their subsequent behaviour, physically and mentally. As an outsider, the invisible periphery reinforces the emotional conflict, and, in turn, rural migrants are further weakened by trying to blend easily into the city community. 


\section{Self-cognition in society}

Up to now, a large body of research has explored the emotional and community experience of migrants in urbanized spaces, probing into how their community sentiments are built upon the axis of differences and transformations (Liu et al. 2010, Du and Li 2010). However, such works concentrate on documenting migrants' emotional experience in given situations rather than considering the different social formation, as the key factor underlying the inevitable intergroup conflict. Noticeably, the countryside and the city are the specific sites where the cultural differences between rural Chinese and urban Chinese are most clear-cut. At this point, it is pertinent to revisit an image of the family unit in the eyes of the Chinese population.

Family (Jia), for Chinese people, is more like a symbolic area of kinship. The ideal family is in fact an extended family living under one protecting roof. In China's countryside, until now, this family type stands for the permanence of a family's full lineage. It is generally well maintained by the populous, extended family, in which the members exceed a dozen, or by all inhabitants in a hamlet which have the same surname (Fukuyama 1996). In terms of a village encircled by a city, I am concerned in this article with the rural home of China as an archetype.

In that sense, the rural and urban parts control a number of differently respective dimensions. First, the rural represents the kinship (clan) family-based social structure while the city mirrors the inclination of a relatively individual-dominating social order; so to speak, the rural and the urban of China translate into 'who we (kinship family) are' and 'who I am'. One great challenge that the newly-urbanite rural people face is the understanding of the notion of the individual and entering into the spirit of the city. Individualism in the context of Chinese history and culture is a deviation (Smith 1992). To a certain extent, the traditional Chinese concept of a man is not presenting the self as an individual person but as one who is inescapably immersed in a group - the family.

Placed into our case study, the ' $l$ ' is formed out of the self-consciousness on his/her activities that leads to the formation of a self-appearance. CZC dwellers have a tendency to grasp themselves as isolated resources and fail to see the others with whom they interact and continue various conversations with. The solo I-oriented city lifestyle, however, does not live in the society of the countryside. For people living in a CZC, his/her social life takes place in the migrant groups that are not given to cooperative activities.

This fact is illustrated in the detail that settlement house dwellers show their non-expectation to sensitive statements concerning their affection for this area - as "an absence of self-belonged group". This passive evaluation towards his-settling situation is also reflected in opinions toward living in a CZC: insecurity due to a lack of "village unit" organization and management model; crowds of unknowns and absence of public services.

Barriers in observing the actions and attitudes of others generate encumbrances in touching with individuals who are not fully acquainted, and this results in CZC dwellers restraining their interaction to peer groups in which the living risks can be minimized to a degree. Passive or negative, the $C Z C$ dwellers have considerable problems in feeling people organized in cooperative group activity. Perhaps the CZC dweller can see, observe, and describe this action; the CZC dweller cannot see himself/herself in such a circle. Standards, for instance, equivalence, reliance, and mutuality are considered as they only apply to their origin-based community relationships in lieu of being outside of these peer groups. For migrants, the peer group is a routinized congregation or community covering a small range: similar kin-relatives or 
physical origin.

This narrow living circle, of course, impedes cooperative activity. Resources are not shared within a framework of reciprocity norms which necessitate migrants to contribute his/her own resources to swell the adaptive potential of the group as a whole. CZC dwellers, for instance, pursue a minimal number of improving community where they are housed, or they are not interested in being outside of the peer group, because they want to make money and save their energy for their own family-oriented behavior within the peer group.

Such a living circle constitutes the typical adaptive mode of many cooperative, kin-based rural communities, and contrast with the individualistic strategies more common within an urban community. It can be argued that the different dimensions we see now do not just bring inevitable emotional conflicts; this definition of self-cognition, together with migrants' role and location in work and at home, makes the CZC a ground for conflicts. In this sense, the CZC is doomed to be a hybrid of going-between, in which modern urban identity and traditional rural identity coexist throughout urbanization. Moreover, a correlated research (Fukuyama 1996, Li et al. 2009) appears to reveal that lodgers' subjective awareness of exclusion treatment, emotional encounters and weakened community networks significantly reduce their positive influence on the cohesion in the city. Also, such factors have had a noticeable effect on their diminishing degree of trust in a wide variety of social relationships.

\section{Social Cohesion}

The emphasis in this paper is on the prevailing attitude towards rural migrants as permanent, second-tier sojourners or 'others' in urban society (Fan 2002). The portrait drawn of them is as outsiders and most are relegated to focusing on a narrow section of industries in frontline production, involved in menial work, restaurants, and low-skilled enterprises (Kam and Li 1999). As a result of their cohesion being grounded in the lower levels of society and in the long absence of stable support or protection from the government, CZC dwellers have naturally formed themselves into self-sufficient groups in their living environments (Zhang et al. 2003, Zhu and Wu 2003).

According to the Japanese philosopher Watsuji (1996), humans are simply the hybrid of individuality and sociality; humanity is constituted, first of all, neither of individuals nor of society, but rather of the dialectical movement between the two. Those principles in China's traditional society represent what makes it possible for people to live in a cooperative community. As a consequence of this, China's traditional society is comprised of networks of well-known acquaintances. In rural China, the principal social configuration and position in kinship is based on the family, that is to say, this cultural orbit determines the social radius which is drawn within the kin-tie groups or lineage bond. However, in a CZC, for the local villagers left behind and the migrant dwellers, they lose their rural identities as they no longer take part in agricultural activities despite their continued ownership of a distant land ( $\mathrm{Li}$ et al. 2009). The former relation based on those lands has already faded away with the collapse of the household organization while the kin bond is broken and it is too distant to be connected with again. Robert Park (1928) calls such a person "the marginal man", who finds him/herself struggling to breathe in two diverse cultural communities.

Zhen (2001) finds that a rural area supports a network of familiar communities, and people live within their well-defined territory. Conversely, a city is a society revolving around the integration of uncertain elements. In Chinese society, the neighbourhood has always been considered as the second layer of social cohesion just next to kinship ties. Before urbanization, a market- 
driven economic society initiated the influence on and change in loosening relations in traditional neighbourhoods. Nevertheless, the effect has been minimal and even though the degree of mutual support has decreased, being an outsider is still often looked down upon by the locals. In addition, the absence of social and psychological support (Li et al. 2009) in the newly adopted city is likely to make it more difficult to engender a positive impression of the new and unknown, particularly since community sentiments are supposed to be built upon shared equal status and contact (Rothwell 2012). The majority of migrants, however, develop their relationship to the world from simply dealing with the land to making a livelihood without the land. They are not familiar with their host destination, nor do they have intimate local kin ties or friendship networks, nor do they make a complete transformation to living a life full of unfamiliar people and new things.

Instead of depending on kinship ties as before, rural migrants rely on the migrant associations established on the same circumstances or place of origin as their emotional source and social connections. Migrant networks are more likely to engender a community that connects migrants, former migrants, and non-migrants in origin and destination areas through ties of 'kinship, friendship, and shared community origins' (Massey et al. 1999). However, migrant networks are more prone to be narrowed down within groups of geographical origin due to their low-level trust of each other in the urban area.

Furthermore, another predicament arises, especially for the young migrants, since on the one hand, they encounter exclusion from the host society, and on the other hand, their identification to rural society becomes weaker and weaker. This ambiguity involves a double negation, that of non-identity with urbanity and rural life which occurs with the majority of migrants. Finally, the migrants face the dilemma of "non-survival in a city or 'non-return' to the countryside", both of which are unfeasible.

Since the start of such difficulties during migrants' mingling in urban areas, my study continues to show what the migrants' basic household survival strategies have been (such as, the separation of home and work duties and self-help on lodging) and how they work in reality (Zhang et al. 2003, Fan et al. 2011). If we can understand the migrants' experiences in their community and the dreams that motivate them to leave their place of origin, we can better see the hidden cultural resonances and gaps. Through these realizations, we suggest practical proposals for housing, such 'floaters', building a harmonious community and creating a convenient urban landscape.

\section{Household survival strategies: The Separation of Home and Work}

One of the features recognized as archetypal of rural families and as an indication of cultural continuity is the wide-reaching relations and close ties between generations as directly shown in the geographical expression of the housing pattern. That is, more than four generations dwell under the same roof. But nowadays, increasing numbers of migrants, estimated at between 20 and 80 million, are moving across county boundaries (Liang and Ma 2004), with a significant proportion moving from rural to urban areas. When arable lands through which people earn their living vanish under the rapid process of urbanization, this clearance categorizes previous countryside villagers differently; one, the house renter's livelihood is altered from "growing grain" to "growing house" (Liu et al. 2010) and some native peasants become well-off landlords through building and leasing (Yan and Yves 2011); two, able-bodied youth villagers become the circular migrant group between home or origin and the place of migrant work. However, the vast majority of migrants were formerly laborers who came alone; over half of them left wives and children behind in the countryside (Stack 2010). 
The main direct influence that migrants face is related to the former family structure and must be simplified or greatly separated from the loss of a physical home place. That is to say, family members who were living in typical conditions would reside in the same place, but in fact they are now living in separate places. This sojourning circumstance has led to a distinctive family form and a household split between two or more spaces. The split-household form of local peasants presents a fairly apparent increasing tendency after lost land. By 1990, the proportion of three-generational and multi-generational families respectively occupied $44 \%$ and $2 \%$, however, both figures fell to $17 \%$ and $1 \%$ by 2007 , accompanying various patterns of increase in household structure (Shao 2008). As in Figure 5, the proportion of single migrants occupies the majority of households, where the spouse and children are all in a home village or the main family members are separated among three places (a couple may work in different cities, while their children are left behind in the home village).

In the split-household formed by sojourning strategies and geographical severance, the function of China's traditional moral framework-family organization, production and the rest of consumption gradually weakens due to geographical alienation. Much more widely accepted is the fact that the family unit keeps providing mutual support, and accommodation, while in this manner achieving the portrayal of "we are family". Consequently, individual migrants are presently living within the extended family sphere in the countryside. Most of them even experience real urban life, but their main values do not fit in properly with the urban communities due to the fracture in household ethics between urban and rural life.

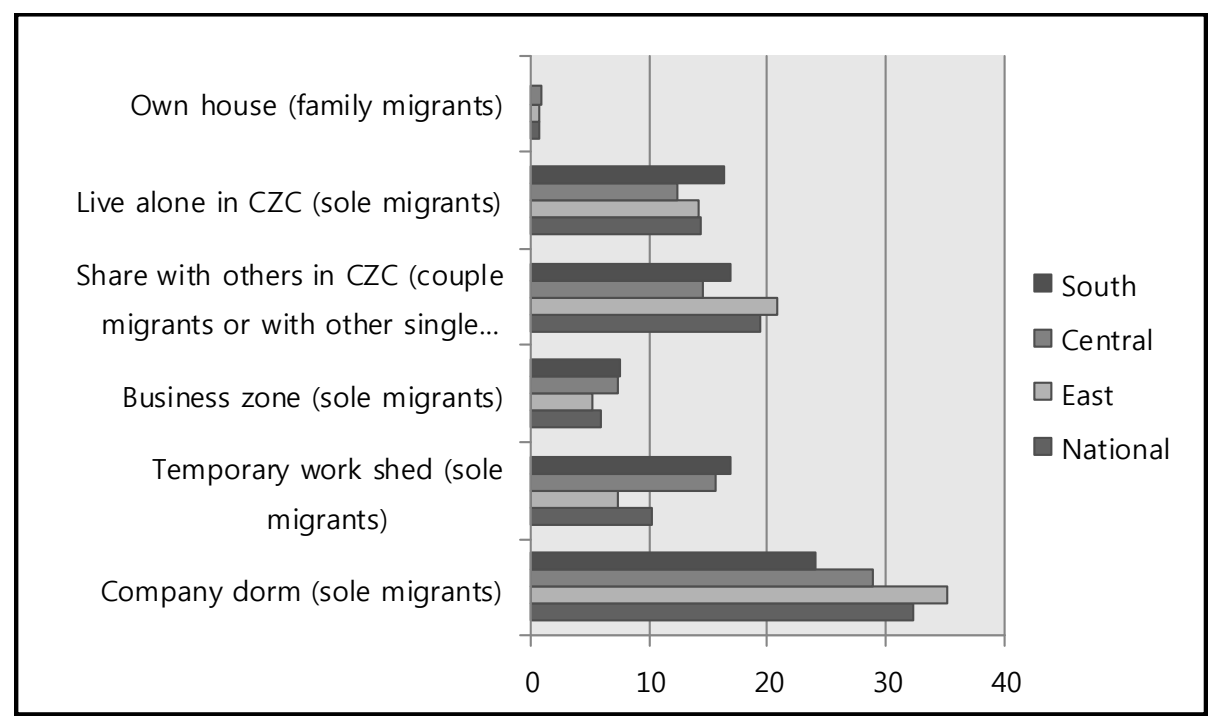

Fig. 5 - Comparison of household situation of the migrants

in different areas of China, 2011

Source: National Bureau of Statistics of China (2011)

\section{Left-behind family}

More importantly, Chinese culture has long depended on the extended family to shelter and bring up children, but as China modernizes, this traditional moral principle is actually being 
called into question. For example, the fracture in family patterns whose reliance on parentbased kinship networks indicates the decisive impact of increased migration. It is estimated that of at least 58 million children are left behind - approximately a quarter of those in rural areas and $1 / 5$ of China's total number of children (Zhu 2010), while among them more than half are taken care of by single parents. It is revealed that $79.7 \%$ are raised by their grandparents' generation, $13 \%$ are put in relatives or friends' hands and those without any guardians occupy around $7.3 \%$ (Suizhou 2006). Instead of having the closest kin ties, in sharp contrast, the left-behind children rely more on their attachment to grandparents due to the absence of their parents. Lengthened absence inevitably alienates parents from their offspring. A long period without face to face contact dooms the children to having an emotional distance from their parents. Furthermore the stability and continuity of the whole family is definitely impaired by the deepening fissure between the parents and their offspring.

In reality, compared to the separation from their offspring, due to obstacles preventing them from being a normal family, the presence of the reunion of couples is evident in the major CZCs. This is due to the fact that in a city, a wide cross-section of menial work is suitable for female laborers, such as housekeeping, restaurant work, and work in sanitation. Faced with these alternatives, unlike the earlier migrants who came to the cities as individuals, most new migrants appear in couple groups, typically due to the low economic return from their agricultural lands.

Nevertheless, the main problem migrant couples face is accommodation. If they live together, they have to rent a house to have an ordinary family life; in which case, it will definitely increase living costs. Otherwise, they can live in a dormitory provided by the employer with other singles. While this couple migration particularly suits migrants except in certain occupations like construction, the couple migration-cycle is hard to realize on account of the lack of stability of working places. In this way, the majority of migrants choose to live in a work shed - a prefabricated form of accommodation. Therefore, this situation discourages the mode of couple migrant-cycle and excludes the rural females from the city, since they would rather stay in the countryside.

\section{Lodging struggle in urban areas The demand for accommodation}

Some of the concern over housing these migrants has tended to be the chief motivation for the housing demand in China during recent years. The masses of young migrants flocking to the cities have created a more severe situation in the supply of low-paid housing which was already in short supply. Admittedly, the number of male migrants commonly outstrips that of females, seeking to earn enough money to raise their children. Further concern for caring for their left-behind extended family has fueled this occupational segregation of migrants in host cities.

For such migrants, low-rent housing is the most common way to lower living costs. Therefore one of the greatest methods is to look for low-cost lodging which makes the CZC in each city so attractive to both rural migrants and the urban poor. This is due to weak urban governance; for one thing, the local government lacks the ability to cope efficiently with the overwhelming demand for housing in the cities. Another fact is that CZCs facilitate the livelihood of the present land-lost peasants, and the introduction of self-financed accommodation has been the most effective method to serve both the needs of migrants and the local government. 
Large-scale flourishing of CZCs might aid to fill the need of availability of affordable housing in cities. That is to say, before the arrival of major reforms in urban comfortable housing programs, the presence of CZCs alludes to the complement of an innovative affordable answer to urban housing difficulties. With regard to the market of housing alternatives in China, since the late 1990s, the 'Comfortable Housing Project' (anju gongcheng) was launched in China; within 20 years, 5 million units of retitled 'Economic and Affordable housing' had been constructed (jingji shiyong fang) (Wu 2002). After one further year had passed, the government added another 5.9 million units; so in 2011, 10 million more units were built. Ultimately, the government seeks to provide affordable housing for $20 \%$ of China's urban population by 2017 , which was reported as part of the $12^{\text {th }}$ Five-Year (2012-2017) plan (Lou 2011).

One of the greatest benefits of increasing low-rent or subsidized housing units being available for low-waged households is to provide respectable, comfortable accommodation in urban areas. However, this institutionalized arrangement does not cover rural migrants so well, as they are typically disqualified from the same treatment as local residents. Also, in any case, the local residents make no exception for migrants, if they do not have the correct registration for the local household residence ${ }^{4)}$.

An improvement has been seen since 2006, in that a great housing bubble continues to spread throughout the whole China, and low-rent housing is in demand on a wide scale for the lower to middle-class migrants ${ }^{5}$ and the lowest placed residents in society. It could be further argued that such a resource as rental housing is imperative for native households; nonetheless, it has not made much of a contribution to rural migrants until now. Recently, in October 2011, the Beijing daily reported that a notice regarding the strengthening of the construction and the management of public-rental housing in Beijing [Guanyyu jiaqiang ben shigonggongzulinzhufangjianshe he guanli de tongzhi] was announced as a new governmental policy. It was revealed that for certain applicants (who continue to work in Beijing for a certain number of years with a stable salary, a temporary residence book and a certificate of public housing fund or social security), their family members have no house in Beijing and they get access to subsidized public-rental housing in Beijing. It deserves to be noted that this is in fact the first time in Beijing that low-renting housing has been open to newcomers.

Despite a number of migrants having benefited from housing policies that were introduced almost 10 years ago, it has often been reported that well-equipped and low-rent apartments built for migrants in many cities have encountered a chilly welcome from rural workers (People's Daily and Xinhua Daily Telegraph 2006) ${ }^{6}$. Why is this? First, there are high commuting costs due to the long distance between work and housing settlements; second,

4) For example, referring to IEAS, in the case of public rental housing in Chongqing China, the candidates need to meet demands issued by Chongqing CCP Municipal Committee and Municipal Government, as follows: 1 . They must be an urban family; 2 . They must be in the low-income category: moderate or minimal wage or a new employee with stable employment and an income source (including college graduates and migrant workers); 3 . They must have a lack of housing or their area of housing is less than $13 \mathrm{~m}^{2}$ per-capita; 4 . the applicant is exempt from the registered permanent residence restrictions.

5) The lower to middle-class migrants consist of people who feel "squeezed" - the income of this class group is slightly better than the general earning public, but they are barred outside eligibility from receiving any government assistance in affording/satisfying decent shelter accommodation needs in the cities of China.

6) The People's Daily and Xinhua Daily Telegraph (2006) reported on the situations of two 'migrant workers' apartments'. According to the reports, the Changsha city government in Hunan Province made an investment to build 618 'migrant workers' apartments' in January 2005, but only 26 apartments have since been rented out. In late 2004, 4,800 apartments were built for migrant workers in Tianjin by Tianjin Port Development Holdings Ltd, but up to now they have attracted only 1,800 rural migrant workers. 
there is a demand for applicants' documents; third, it is the result of construction, the migrantfocused work domain, normally supplies free sheds (a dormitory on a construction site) to meagre-waged migrant workers; four, the rejection of accommodation shared with other people which is not acceptable to couple migrants.

It is not surprising that the huge demand and building costs have put the government in a very awkward position, plus the need for several additional documents. As a result, for the next several years, the former villagers in a CZC will continue to maximize the housing units for the constantly arriving migrants. However, as well-received enclaves for migrants, CZCs normally bear a resemblance to slums in several of their nastiest features (Gransow 2010), lacking unifying arrangements or state intervention. Here, I suggest a decent model for a new CZC design which incorporates traditional Tulou architectural essentials to create a sense of southern Min identity (the Hakka of China).

\section{Tulou housing case}

Collective housing (Tulou housing) was built in 2008 on the outskirts of China's biggest migrant -receiving city - Guangzhou in the Guangdong province of China. This project (Fig. 6) could be considered as a relatively successful case of low-rent housing in the area, according to the regulation requirements of the local government. Namely, a certain percentage of the units in large scale housing developments need to be of lower lease for meagre-waged workers. In this project, the larger housing complex which is outsized is of little worth, because the dwellers are comprised of few people; the average number of residents per house in most migrant families is no more than three or four. For these rural migrants, what is preferential is above all to house a normal family, however small it is. The offer of a separate room for the migrants' own family is not purely a conscious matter of people's privacy, but it confirms the increasing human concerns of the floaters - a rising attention to families' internal life - and the necessity to convey this concept of 'we are family' in physical means. Together with the equivalent housing assignment of the new Tulou, 287 units are expected to accommodate 1800 people, of which 245 are apartments for a lease of $40 \mathrm{~m}^{2}, 24$ are to be used as dormitories and 18 will function as hotel rooms. The lodging circumstances present a sharp comparison with the living situation in CZCs.

In the new Tulou project, the housing conditions involved with providing both an intimate interior and a sheltered exterior present the original imprint of the Hakka's heavily-defended spherical, multi-household earthen structure. Within the constrained space available, the central-focused arrangement resonates consciously the organization of the internal and the exclusion and the resistance of the external. This configuration is an auxiliary implication of the large conversion from the insecure fringe of the city to the big communal houses. Reviewing the objective of this new form of housing, the aims of the design are (Mallick 2010):

- $\quad$ To provide easy access to affordable apartments for low income rural migrants and the urban poor group;

- $\quad$ To provide living spaces that enable a community to evolve and to allow it to emphasize the sharing of the interpersonal or of a collectivity and it fosters the nature of intermediary individuals;

- $\quad$ To provide living spaces which are well lit, ventilated, comfortable and protected.

This new Tulou building has been built and designed for all Chinese to dwell in, without the institutional limitations of the rural/urban household residences or local/outside inhabitants. Moreover, such a construction is an exceptional experiment and a project built with the 


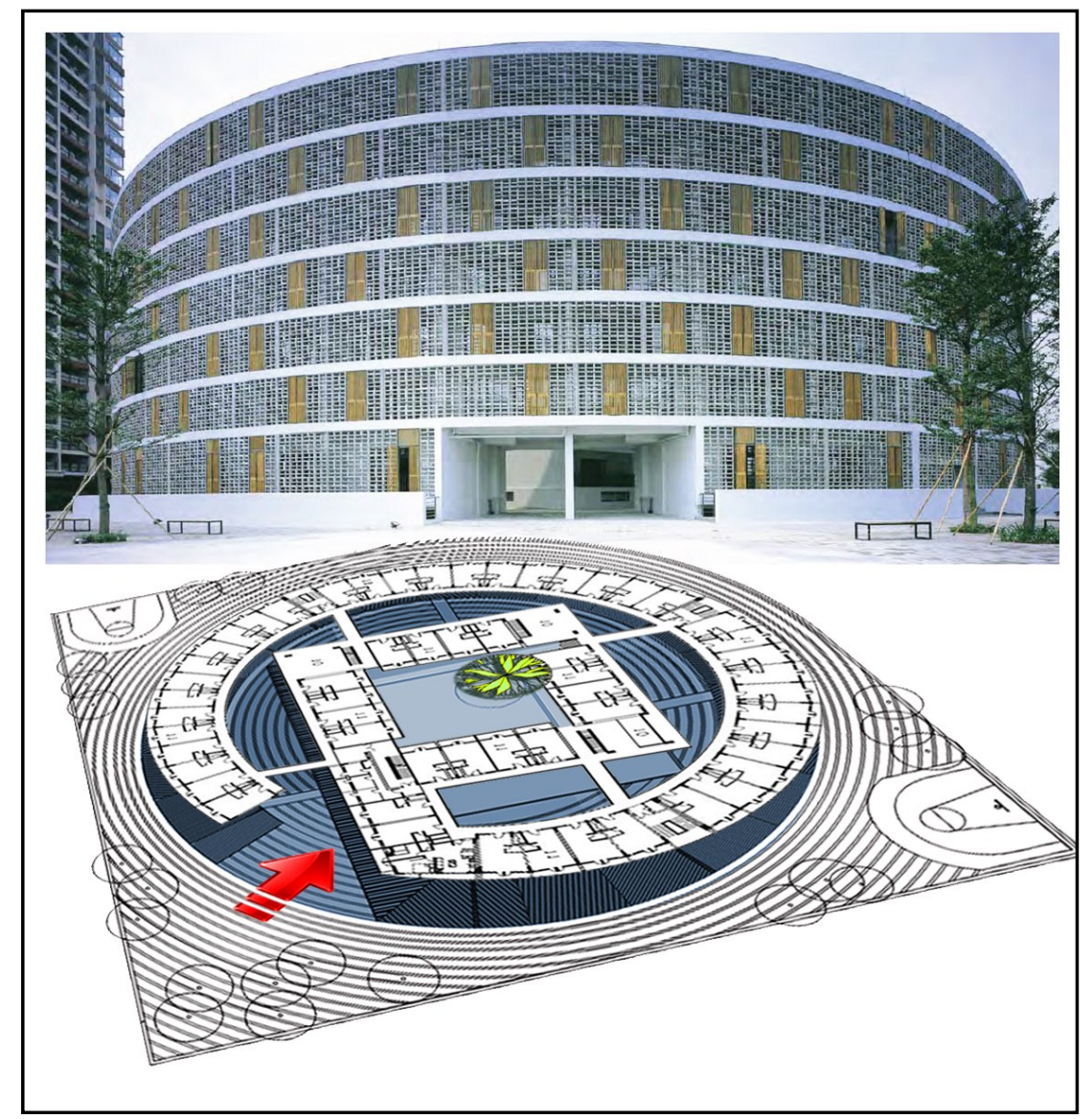

Fig. 6-Collective Housing in Tulou Guangdong province of China Source: Mallick (2010)

absence of the government and its developer (Shenzhen Vanke Real Estate Company) was not concerned with the profit. This can be considered a decent approach in response to the dilemmas posed to migrant workers in search of affordable accommodation. Both the practices of finance and improved housing policy proceed in the absence of state participation in such matters as site selection, and the dwellers' status restriction. This is even though $C Z C$ case studies show that houses are often coupled with the creation of a shantytown and squatter settlements. For a general perspective, both (CZCs and Tulou housing) are undeniably becoming a buffer zone for rural migrants before the government demolishes the Hukou policy and they make sure of their status within a host city.

\section{Conclusion}

This examination of the CZC has emphasized three main points: first, throughout the history of China, rural migrants have faced several forms of inherent social and political discriminatory treatment that have had a direct influence on their self-cognition in host cities. Secondly, the 
massive movement of the rural population during the speedy urbanization presents two key conflicts, self-identity of twilight zones and weak social cohesion. This causes the $C Z C$ to be the 'first step' for floaters blending into the urban community. In any case, the CZC could be profiled as means of segregation in host societies and congregation of the outsiders.

In this context, in order to survive in a host city, the separation of home and work is understood as the inevitable consequence of the survival strategies of migrants. The fracture in traditional Chinese family patterns, together with rural migrants' self-location of work and home, has become an arena of conflict. The reunion of a natural family remains only a dream for most migrants. Normally, for the sake of children and a better life, they go to the city alone or with a spouse, but the remaining family (children, parents and parents-in-law) live in the countryside. The characteristically bare-boned and sub-standard environment in CZCs echoes these migrants' craving to have better lives, representing the rural-urban status of transformation in cities (Hsing 2012); while facing sacrifices through their split-families and the livelihoods they pursue in their day-to-day lives. The welcoming of CZCs plays a supporting role in migrants' struggles faced with such disparities, as standards of class status and a longing to change their family's destiny.

Finally, a sizable number of rural migrants who float towards the city are doomed to be treated as outsiders, and relegated to concentrating on the availability of low-level jobs in society. Lowwaged economic situations do not allow them to afford better-settled housing in the city centre; rather they must live in a CZC or in other run-down and deprived areas. Since 2003, the Chinese State Council has issued a series of policies on the protection of migrant workers' rights in terms of improvements in their living conditions and forming a better living environment (China Labour Bulletin 2006) although the government still only writes the names of the nonrural natives on the applicants' list of affordable housing.

At the same time, the urban Tulou case demonstrates that in the absence of government participation (e.g. subsidized land from a government-funded program), the private real estate developers first offered another favorable model for decently accommodating low-waged workers. In more detail, by focusing on the housing suppliers, the urban Tulou is a unique experiment in terms of having low-rent housing being invested in by developers and it could become a promising example of an affordable, comfortable and visually attractive urban model for the expanding number of low-renting migrants. However, one point that cannot be ignored is the importance of making every effort to enable the Chinese people to live a happier life with more dignity, as proposed by the Chinese premier Wen Jiabao ${ }^{7)}$.

Nowadays, affordable housing in all cities in China is all organized by the local government, and the gap between demand and supply is partially due to unilateral investments. It could be further argued that in view of the current land organization in China, only the state has the ultimate authority to decide on whom the urban land belongs to and, to some degree, it is at the disposal of the various levels of governments (Zuo 2008). The importance of the urban Tulou case allows us to reassess the hidden shortage of affordable housing projects in China in recent times and it can be developed into a reproducible archetype in China's cities. By doing this, the respective local government can create more favorable housing policies and also

7) During the 3rd annual plenary session of the 11th National People's Congress held in March 2010, Chinese premier Wen Jiabao declared: 'Let people live with greater dignity'. It indicates that with the rapid economic development of recent years, the Party and the country should endeavor to enable the Chinese people to live a happier life with greater dignity, with policies such as fair income distribution and the easing of the predicament of accommodating rural migrant workers floating into the fabric of urban society. Available online: http://topics.redcome.com/html/report/2205412-1.htm. 
provide economic assistance to this project, such as making low-cost land available to real estate developers if their construction projects address the needs of low-renting rural migrants.

\section{References}

BAILEY M., GIROUX M. (1998), Relocation of Custodial Parents. Final Report, Status of Women Ottawa, Canada.

BURRELL K. (2011), Going steerage on Ryanair: cultures of migrant air travel between Poland and the UK, Journal of Transport Geography 19, 1023-1030.

CHINA LABOUR BULLETIN (2006), Why don't rural migrant workers live in government -subsidized low-rent apartments, [http://www.clb.org.hk/en/node/39615].

CHENG T. J., SELDEN M. (1994), The origins and social consequences of China's Hukou system, The China Quarterly 139, 644-668.

CURRAN S. R., SAGUY A. C. (2001), Migration and cultural change: A role for gender and social networks?, Journal for International Women's Studies 2 (3), 54-77.

DU H. M., LI S. M. (2010), Migrants, urban villages, and community sentiments: a case of Guangzhou, China, Asian Geographer 27 (1-2), 93-108.

EISENSTADT S. N. (1953), Analysis of patterns of immigration and absorption of immigrants, Population Studies: A Journal of Demography 7 (2), 167-180.

FAN C. C. (2002), The elite, the natives, and the outsiders: migration and labour market segmentation in urban China, Annals of the Association of American Geographers 92 (1), 103 124.

FAN C. C., SUN M. J., ZHENG S. Q. (2011), Migration and split households: a comparison of sole, couple, and family migrants in Beijing, China, Environment and Planning A 43, 2164-2185.

FENG, X. Y. (2011), Study on transformation of Chengzhongcun in Beijing (Beijing Chengzhongcun gaizao de diaochayusikao), China Reform Forum [http:// www.chinareform.org.cn/forum/crf/69/paper/201008/t20100804_39040.htm].

FOUCAULT M. (1990), The history of sexuality, Vol 1: An Introduction. Trans, Robert Hurley, Pantheon Books, New York, USA.

FUKUYAMA Y. F. (1996), Trust: the social virtues and the creation of prosperity, Free Press.

GLAESER E. L., KAHN M. E, JORDAN R. (2008), Why do the poor live in cities? The role of public transportation, Journal of Urban Economics 63 (1), 1-24.

GRANSOW B. (2010), Slum formation or urban innovation? - Migrant communities and social change in Chinese megacities, Proceeding from Rural-Urban Migrations in Mega Cities and 'Mega-Slums' Our Common Future, Essen, Germany.

GOODKIND D., WEST L. A. (2002), China's floating population: definitions, data and recent findings, Urban Studies 39 (12), 2237-2250.

GUO F., ZHANG Z. (2006), Transforming urban villages: social stratification in migrant communities in China, presented at the ACESA Annual Conference 2006 - Emerging China: Internal challenges and global implications, Melbourne, Australia.

HRSSD (2011), Development Statistic Bulletin by Human Resources and Social Security Department of PRC, China.

HSING Y. T. (2012), The great urban transformation: politics and property in China, Oxford University Press, USA.

IEAS (2010), The State of China's Cities 2010/2011: Better City, Better Life, China Science Centre of International Eurasian Academy of Sciences China Association of Mayors, and UN-HABITAT, Foreign Language Press, China.

JOHN L. (2002), The new Chinese city: globalization and market reform, WileyBlackwell, Oxford. 
JOHN R., MOORE R. (1967), Race, community and conflict: a study of Sparkbrook, Oxford University Press for the Institute of Race Relations, London, UK.

JOHN K., SONG L. (1995), Towards a labour market in China, Oxford University Press, USA.

KAM W. C., LI Z. (1999), The Hukou system and rural-urban migration in China: processes and changes, China Quarterly 160, 818-855.

LAURENCE J. C., MA F. L. (2004), Restructuring the Chinese city: Changing Society, Economy and Space, Routledge, London, UK.

LI T. (2008), The Chengzhongcun land market in China: boon or bane? - A perspective on property rights, International Journal of Urban and Regional Research 32 (2), 282-304.

LI S. M., ZHU Y. S., LI L. M. (2009), Community type, gateness and neighborhood experiences: a study of Guangzhou, China, Occasional paper, Hong Kong Baptist University, Centre for China Urban and Regional Studies 93.

LIAN Y. M. (2012), Report on the innovation of China's social administration. 2012, Social Sciences, Academic Press of China, China.

LIANG Z., MA Z. D. (2004), China's floating population: new evidence from the 2000 census, Population and Development Review 30 (3), 467-488.

LIU X. L., LIANG W. (1997), Zhejiangcun: social and spatial implications of informal urbanization on the periphery of Beijing, Cities 14 (2), 95-108.

LIU Y. T., HE S. J., WU F. L., CHRIS W. (2010), Urban villages under China's rapid urbanization: Unregulated assets and transitional neighbourhoods, Habitat International 34 (2), $135-144$

LOU J. B. (2011), China's massive affordable housing project: how it works and my concerns. China Debate, [http://www.chinadebate.com/2011/08/chinas-massive-affordabalehousing-project-how-it-works-and-my-concerns, Accessed 22 August 2011].

MALLICK F. (2010), 2010 on Site Review Report: Tulou Collective Housing, China.

MASSEY D. S., JOAQUIN A., HUGO G., KOUAOUCI Ali. (1999), Worlds in motion: understanding international migration at the end of the millennium, Oxford University Press, USA.

NBSC (National Bureau of Statistics of China) (2012), Chinese statistical yearbook 2012, China Statistics Press, Beijing.

PARK R. (1928), Human migration and the marginal man, The American Journal of Sociology 33 (6), 881-893

ROSSI P. H. (1980), Introduction to second edition, in P. H. Rossi, Why families move. Beverly Hills, Sage, CA.

ROTHWELL J. T. (2012), The effects of racial segregation on trust and volunteering in US cities, Urban Studies 49 (10), 2109-2136.

SHAO F. (2008), The influence of household structure change upon the dwelling and mode of community for the aged - case study of urban village in Qingdao, Economic 7 (Chinese version).

SHELLER M., URRY J. (2006), The new mobilities paradigm, Environment and Planning A 38, 207-226.

SMITH D. C. (1992), The Chinese family in transition: implication for education and society in modern Taiwan, Proceeding from the Comparative Education Association/World Bank Seminar, Spring, Annapolis Maryland.

STACK M. K. (2010), China raising a generation of left-behind children, Los Angeles Times [http://articles.latimes.com/2010/sep/29/world/la-fg-china-left-behind-20100930, Accessed on 29 September 2010].

SUIZHOU (2006), Baidu Encyclopedia [http://baike.baidu.com/view/109106.htm, Accessed on 5th May 2006]. 
WATSUJI T. (1996), Rinrigaku: ethics in Japan, trans. Yamamoto Seisaku and Robert E. Carter, State University of New York Press, Albany.

WU W. P. (2002), Migrant housing in urban China: choices and constraints, Urban Affairs Review 38 (1), 90-119.

XU F. (2008), Gated communities and migrant enclaves: the conundrum for building 'harmonious community/shequ', Journal of Contemporary China 17 (57), 633-651.

YAN S., YVES Z. N. (2011), Urban villages and housing values in China, Regional Science and Urban Economics 42, 495-505.

YU X. J. (2008), The distribution of China's floating population in Guangzhou and other 9 provinces (Zhongguoliu dong renkou fen bujijuguang dong jiangsudeng 10sheng zhanliucheng duo), [http://www.china.com.cn, Accessed on 23 October 2008].

ZHANG L., SIMON X. B., TIAN J. P. (2003), Self-Help in housing and Chengzhongcun in China's urbanization, International Journal of Urban and Regional Research 27 (4), 912-937.

ZHEN Y. F. (2001), Trust (Xinrenlun), China Radio and Television Press, China.

ZHIFENG Z. (2009), Research on the Beijing rural villages' classification \& development under urbanization, Conference Proceedings, Qu L., Yang C., Hui X., Sepúlveda D. (Eds.), The New Urban Question - Urbanism beyond Neo-Liberalism, International Forum on Urbanism, Amsterdam/Delft, 1387-1394.

ZHU H. L. (2010), Study on left behind children of China, [http://www.chinaedunet.com/ kh/thesis/content.asp?id=436].

ZHU Q. Z., WU H. F. (2003), The cultural role and perception of agriculture in China, Roles of Agriculture Project International Conference, Rome, Italy.

ZUO X. J. (2008), China's decentralization and its impact on urbanization, in Shinichi Ichimura and Roy Bahl, Decentralization Policies in Asian Development, World Scientific Publishing Company.

Initial submission: 15.10.2013

Revised submission: 06.05.2014

Final acceptance: 15.12.2014

Correspondence: Department of Architecture \& Architectural Engineering, Seoul National University, 1 Gwanak-ro, Gwanak-gu, Seoul, South Korea

Email: xueni.peng@gmail.com 